\title{
openheart Reducing radiation exposure during atrial fibrillation ablation using lectures to promote awareness
}

\author{
Yosuke Miwa, ${ }^{\oplus 1}$ Akiko Ueda, ${ }^{2}$ Michitsugu Komeda, ${ }^{1}$ Shinsuke Takeuchi, ${ }^{1}$ \\ Mika Nagaoka, ${ }^{1}$ Yuichi Momose, ${ }^{3}$ Noriko Nonoguchi, ${ }^{1}$ Kyoko Hoshida, ${ }^{1}$ \\ Mutsumi Enomoto, ${ }^{1}$ Ikuko Togashi, ${ }^{1}$ Akiko Maeda, ${ }^{4}$ Yo Hagiwara, ${ }^{5}$ Toshiaki Sato, ${ }^{1}$ \\ Kyoko Soejima ${ }^{1}$
}

To cite: Miwa Y, Ueda A, Komeda M, et al. Reducing radiation exposure during atrial fibrillation ablation using lectures to promote awareness. Open Heart 2019;6:e000982. doi:10.1136/ openhrt-2018-000982

Received 2 December 2018 Revised 9 February 2019 Accepted 18 March 2019

Check for updates

C) Author(s) (or their employer(s)) 2019. Re-use permitted under CC BY-NC. No commercial re-use. See rights and permissions. Published by BMJ.

${ }^{1}$ Cardiology, Kyorin University Hospital, Tokyo, Japan

${ }^{2}$ Cardiac Morphology Unit, Department of Paediatrics, Royal Brompton Hospital, London, UK ${ }^{3}$ Division of Cardiology, Second Department of Internal Medicine, Kyorin University School of Medicine, Tokyo, Japan ${ }^{4}$ Division of Advanced Arrhythmia Management, Department of Cardiology, Kyorin University Hospital, Tokyo Japan

${ }^{5}$ Division of Engineering, Kyorin University Hospital, Tokyo, Japan

Correspondence to Dr Kyoko Soejima; skyoko@ks. kyorin-u.ac.jp

\section{ABSTRACT}

Objective Recently, concern has increased regarding the hazards of radiation exposure in patients and laboratory staff. Since the numbers of complex catheter ablations (CA) performed, duration of procedure times, and need for multiple sessions have increased, radiation exposure during each session needs to be minimised. Our study aimed to assess the impact of awareness on radiation exposure during $\mathrm{CA}$ for atrial fibrillation (AF). Methods Mini-course lectures was delivered to the physicians and staff in the electrophysiology division. Its effect on the fluoroscopic time and radiation dose during $\mathrm{AF}$ ablation before (Group I, $\mathrm{n}=70$ ), shortly after (Group II: $n=70$ ) and remotely after the mini-lecture (Group III, $\mathrm{n}=70$ ) were evaluated. Patient demographics, preoperative testing and procedural parameters were collected.

Results The fluoroscopic time significantly reduced after the lecture (Group I and II: $25.1 \pm 10.0$ and $15.1 \pm 7.3 \mathrm{~min}$, respectively $(\mathrm{p}<0.0001))$, and remained so in Group III (13.0 $\pm 5.4 \mathrm{~min})$, despite the increase in the number of persistent AFs. The radiation dose also significantly reduced (Groups I, II, III: 295.0 263.0 , $109.6 \pm 103.5$ and $110.1 \pm 89.6 \mathrm{mGy}$, respectively $(p<0.0001))$.

Conclusion Awareness on radiation exposure led to a significant reduction in fluoroscopic time and radiation dose during $\mathrm{CA}$ for $\mathrm{AF}$, the effect of which persisted even to remote periods following the procedure.

\section{INTRODUCTION}

Atrial fibrillation (AF) is the most common arrhythmia, and catheter ablation (CA) has become an established therapy to control recurrent $\mathrm{AF}^{1} \mathrm{CA}$, especially for complex arrhythmias, such as AF requires longer procedure times and may require multiple procedures. As there are risks associated with exposure to medical radiation during these procedures, it is essential to keep the ALARA (as low as reasonably achievable) principle.

Radiation exposure is associated with the risk of brain tumours in the operators, ${ }^{2}$ and

\section{Key questions}

What is already known about this subject?

- Atrial fibrillation (AF) ablation has become an established therapy to control recurrent AF which could require longer procedure times and may require multiple procedures. Although some special tools or techniques have been introduced to reduce the radiation exposure, the ability of simple lecture to promote the awareness to reduce the radiation exposure in AF ablation is unclear.

What does this study add?

- There have been limited information regarding effects of simple lecture to promote the awareness in catheter ablation even though it has been reported in coronary angiography and right heart catheterisation.

How might this impact on clinical practice?

- Promoting awareness on radiation exposure reduced the radiation exposure during $\mathrm{AF}$ ablation, and the effects of the educational intervention persisted even at remote periods following the procedure.

lens and skin injury in both the patients and the staff. ${ }^{3}$ Since the radiation dose from a single procedure is low, the risk to the medical staff is often underestimated. However, cumulative doses could contribute to significant risks, especially among physicians who perform many complex cases.

Although three-dimensional electroanatomical mapping systems (3D-EAM) have contributed to a reduction in radiation exposure, ${ }^{45}$ further reduction is necessary. ${ }^{6}$ Previous studies show that radiation exposure could be significantly reduced during percutaneous coronary intervention and cardiac catheterisation by promoting awareness. $^{7-9}$ The aim of this study was to evaluate the short-term and long-term impact of promoting awareness of radiation exposure during CA for AF. 


\section{METHOD}

\section{Patients}

We evaluated the radiation dose used in $\mathrm{CA}$ for $\mathrm{AF}$ using a fluoroscopic system (INFX-8000V, Toshiba, Tokyo, Japan). Pulse fluoroscopy rates were preprogrammed at 3.75 frames per second, and the frame rate was set at six frames per second. X-ray beam collimation was encouraged to minimise the field of view.

A mini-course lecture was delivered to the catheter laboratory staff, including the electrophysiology fellows, physicians, medical engineers and nurses in the first week of July 2015. Seventy consecutive patients for each group were selected to compare the effects of awareness on radiation exposure prior to the lecture (Group I: from August 2014 to June 2015), shortly (immediately following) after the course (Group II: from August 2015 to November 2016) and remotely (one and a half years) after the lecture (Group III: from January 2017 to August 2017). Their baseline characteristics and procedural data were compared. The acute complications and complications at the 1-month visit were evaluated.

\section{Mini-course lecture}

The mini-course lecture on radiation exposure was administered to the electrophysiology team. It consisted of two 1-hour lectures, and included basic concepts on radiation, ionising effects and practical methods to reduce radiation exposure during $\mathrm{CA}$ such as minimisation of cine acquisition, maximal effort to avoid the left anterior oblique view, higher position of the patient table, optimisation of collimation and so on.

\section{Catheter ablation}

The patients were sedated with dexmedetomidine and fentanyl, and their arterial blood pressures were monitored through a femoral artery. An oesophageal temperature probe (Esophastar, Japan Lifeline) was inserted. The radio frequency application was stopped immediately if the temperature reached $40^{\circ} \mathrm{C}$ to prevent the oesophageal injury. A 20-pole electrode catheter (BeeAT, Japan Lifeline) was placed in the coronary sinus for internal cardioversion, and a quadripolar catheter was placed at the right ventricular apex. In addition, an intracardiac echocardiographic catheter, a 20-pole ring catheter, and an ablation catheter were placed.

As an ablation catheter, a contact force sensing catheter (ThermoCool SmartTouch or ThermoCool SmartTouch SF, Biosense Webster; or TactiCath Quartz, St Jude Medical) was used in all cases with either a CARTO or an Ensite system. Voltage and activation maps were obtained using a circular mapping catheter. Following the pulmonary vein antrum isolation (PVAI), the presence of a bidirectional block was confirmed by pacing with and without a bolus injection of adenosine. Following the PVAI, a voltage map of the left atrium was obtained. Further ablation and modification of the substrate were performed only if a low voltage area $(<0.5 \mathrm{mV})$ was present. From September 2016 onwards, the ablation strategy for persistent AF had changed from low voltage modification to left atrial posterior wall isolation (LAPI).

Cavo-tricuspid isthmus (CTI) and mitral isthmus linear ablations were performed if CTI-dependent or perimitral atrial flutters, respectively, were documented or induced. Frequent atrial extrasystoles or induced macroreentrant atrial tachycardias were targeted. In all patients, Warfarin was maintained at an international normalised ratio of 2-2.5 and was continued on the day of the procedure. For patients on direct oral anticoagulants, the morning doses were skipped and reinitiated after the ablation. Heparin was given prior to the transseptal puncture, and the activated clotting time was maintained between 250 and 350 $\mathrm{s}$ throughout the procedure. After the procedure, Protamine was administered, and haemostasis was achieved.

\section{Follow-up}

Patients were followed-up according to our regular practice at visits to the clinic at 2 weeks, 1, 3, 6 and 12 months following the procedure. On the day of the visit, a 12-lead ECG and 24 hours Holter monitoring were performed to check for recurrence. If an atrial tachyarrhythmia lasting longer than $30 \mathrm{~s}$ was recorded, a recurrence was diagnosed.

\section{Statistics}

Categorical data were described as numbers and percentages. Numerical data were described as means and SD. Comparisons were performed using the Mann-Whitney test for skewed data and the Student's t-test for non-skewed data between the groups. To compare categorical data, the Fisher's exact and $\chi^{2}$ tests was used. $\mathrm{P}$ values $<0.05$ were considered statistically significant. Multivariate analysis of variance (MANOVA) was conducted considering the possibility that clinical factors including left atrial dimension, body mass index (BMI) and type of $\mathrm{AF}$ (paroxysmal or persistent) influenced the results of fluoroscopic time and radiation dose.

\section{RESULTS}

\section{Patient characteristics}

A total of 210 patients were enrolled. There were no significant differences in the height, weight, or BMI of patients, which could affect the radiation dose, between the three groups (table 1). However, Group III included more persistent $\mathrm{AF}(\mathrm{p}<0.0001)$, as the majority of paroxysmal AF patients underwent cryoballoon ablation from May 2016 onwards. Additionally, the approach to persistent AFs had changed from September 2016 onwards, when we added LAPI, in addition to PVAI, for patients with persistent $\mathrm{AF}$.

\section{Procedure parameters}

The procedure parameters are shown in table 2. PVAI was performed in all patients. There was no significant difference between the groups in the need for additional ablation, such as CTI linear ablation, low-voltage zone modification, superior vena cava (SVC) isolation, and 


\begin{tabular}{|c|c|c|c|}
\hline & $\begin{array}{l}\text { Group I } \\
(n=70)\end{array}$ & $\begin{array}{l}\text { Group II } \\
(n=70)\end{array}$ & $\begin{array}{l}\text { Group III } \\
(n=70)\end{array}$ \\
\hline Age (years old) & $64 \pm 10$ & $67 \pm 13$ & $68 \pm 9$ \\
\hline Gender (male, \%) & $48(69 \%)$ & $46(66 \%)$ & $43(61 \%)$ \\
\hline Height (cm) & $163.5 \pm 9.1$ & $162.1 \pm 17.1$ & $164.4 \pm 7.7$ \\
\hline Weight (kg) & $63.2 \pm 12.8$ & $63.4 \pm 14.5$ & $64.2 \pm 14.4$ \\
\hline BMI & $23.5 \pm 4.0$ & $23.7 \pm 4.3$ & $23.8 \pm 4.0$ \\
\hline $\begin{array}{l}\text { Persistent atrial } \\
\text { fibrillation }(n, \%)\end{array}$ & $17(24 \%)$ & $20(29 \%)$ & $53(76 \%) *$ \\
\hline $\begin{array}{l}\text { Congestive heart } \\
\text { failure }(n, \%)\end{array}$ & $12(17 \%)$ & $11(18 \%)$ & $18(26 \%)$ \\
\hline Hypertension (n, \%) & $29(41 \%)$ & $40(57 \%)$ & $37(53 \%)$ \\
\hline Diabetes (n, \%) & $8(11 \%)$ & $13(19 \%)$ & $8(11 \%)$ \\
\hline Stroke $(\mathrm{n}, \%)$ & $3(4 \%)$ & $5(7 \%)$ & $2(3 \%)$ \\
\hline $\begin{array}{l}\text { Vascular disease (n, } \\
\%)\end{array}$ & $2(3 \%)$ & $1(1 \%)$ & $7(10 \%)$ \\
\hline CHADS2 & $1.3 \pm 1.1$ & $1.7 \pm 1.1$ & $1.6 \pm 1.0$ \\
\hline CHA2DS2-VASC & $1.8 \pm 1.3$ & $2.3 \pm 1.4$ & $2.4 \pm 1.4$ \\
\hline $\begin{array}{l}\text { Left atrial dimension } \\
(\mathrm{mm})\end{array}$ & $37.4 \pm 7.7$ & $36.9 \pm 5.9$ & $40.2 \pm 6.4$ \\
\hline $\begin{array}{l}\text { Left ventricular } \\
\text { ejection fraction (\%) }\end{array}$ & $61.8 \pm 8.8$ & $60.3 \pm 10.2$ & $60.7 \pm 8.3$ \\
\hline
\end{tabular}

${ }^{*} \mathrm{p}<0.0001$.

BMI, body mass index.

mitral isthmus linear ablation. However, more patients in Group III had LAPI due to the change in treatment strategy for persistent AF. Contact force monitoring was used for a majority of the patients. However, since the number of Ensite cases increased from December 2016 and TactiCath became available from May 2017, fewer patients in Group II were treated with contact force monitoring as shown in table 2.

The fluoroscopic times in patients treated after the mini-lecture were significantly shorter than those treated before $(15.1 \pm 7.3$ and $25.1 \pm 10.0 \mathrm{~min}$, respectively $(\mathrm{p}<0.0001))$, and it remained short in the remote period after the procedure $(13.0 \pm 5.4 \mathrm{~min}(\mathrm{p}<0.0001))$. The radiation doses in patients treated after the lecture were also significantly lower than those in patients treated before the lecture (109.6 \pm 103.5 and $295.0 \pm 263.0 \mathrm{mGy}$, respectively $(\mathrm{p}<0.0001))$, and remained low in remote period following the procedure $(110.1 \pm 89.6 \mathrm{mGy}(\mathrm{p}<0.0001))$. MANOVA test also revealed that the results have validity $(p<0.0001$ for all). The fluoroscopic time and radiation dose for each patient is shown chronologically in figures 1 and 2, and it is clear that both have reduced following the mini-lecture and the trend remained so even at remote periods after the lecture. The reduction in radiation doses was larger when compared with the reduction in fluoroscopic times.

\section{Procedure outcome}

In all patients, PVAI was achieved. SVC, LAPI, CTI and mitral isthmus linear ablation were completed, and the presence of bidirectional blocks was confirmed in all patients in whom the target lesions were present. There was no significant difference in the long-term outcomes (12 months) between the three groups $(79 \%, 86 \%$ and $83 \%$ were free from AF recurrence, respectively). There were two complications in Group I (haematoma and pericardial effusion), and none in Groups II and III.

Table 2 Procedure characteristics

\begin{tabular}{|c|c|c|c|}
\hline & $\begin{array}{l}\text { Group I } \\
(n=70)\end{array}$ & $\begin{array}{l}\text { Group II } \\
(\mathrm{n}=70)\end{array}$ & $\begin{array}{l}\text { Group III } \\
(\mathrm{n}=70)\end{array}$ \\
\hline Pulmonary vein antrum isolation & $70(100 \%)$ & $70(100 \%)$ & $70(100 \%)$ \\
\hline Cavo-tricuspid isthmus linear ablation & $12(17 \%)$ & $12(17 \%)$ & $18(26 \%)$ \\
\hline Supra vena cava isolation & $3(4 \%)$ & $7(10 \%)$ & $6(9 \%)$ \\
\hline Left atrial posterior wall isolation & $1(1 \%)$ & $5(7 \%)$ & $56(80 \%)^{*}$ \\
\hline Mitral isthmus linear ablation & $2(3 \%)$ & $3(4 \%)$ & $4(6 \%)$ \\
\hline Low voltage zone modification & $2(3 \%)$ & $0(0 \%)$ & $1(1 \%)$ \\
\hline Other atrial tachycardia & $2(3 \%)$ & $2(3 \%)$ & $5(7 \%)$ \\
\hline Procedure time (min) & $251 \pm 53$ & $250 \pm 58$ & $188 \pm 38 \dagger$ \\
\hline Fluoroscopic time (min) & $25.1 \pm 10.0$ & $15.1 \pm 7.3$ * & $13.0 \pm 5.4$ * \\
\hline Radiation dose (mGy) & $295.0 \pm 263.0$ & $109.6 \pm 103.5^{*}$ & $110.1 \pm 89.6$ * \\
\hline 3D-EMS (CARTO/Ensite/Rhythmia) & $64 / 6 / 0$ & $46 / 24 / 0 \neq$ & $31 / 38 / 1$ * \\
\hline Contact force monitoring catheter & $64(91 \%)$ & $46(66 \%) \ddagger$ & $69(99 \%)$ \\
\hline
\end{tabular}

${ }^{*} \mathrm{p}<0.0001$.

$\dagger p=0.002$.

$\ddagger \mathrm{p}=0.0003$.

3D-EMS, three-dimensional electroanatomical mapping systems. 


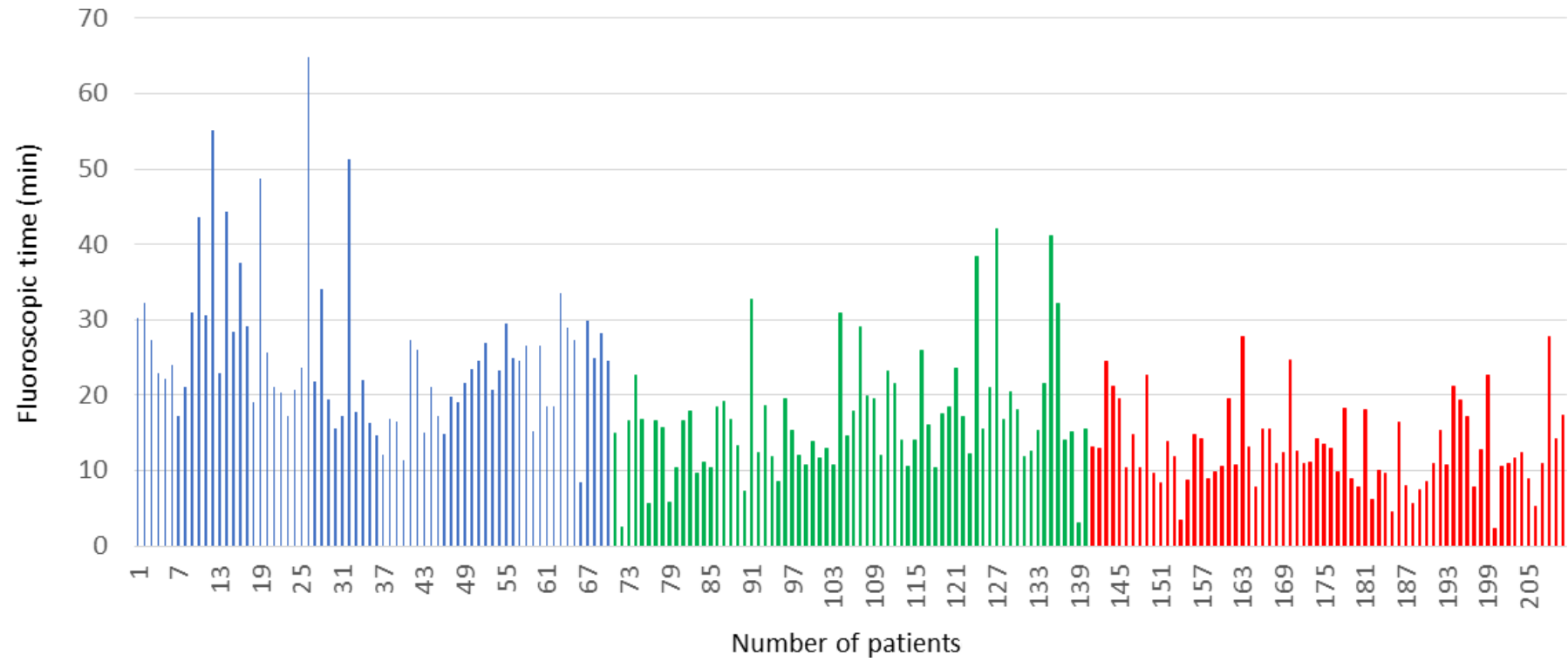

Figure 1 Chronological fluoroscopic time for each patient. Blue bar: patients prior to the mini-lecture (Group I); green bar: patients immediately after the mini-lecture (Group II); red bar: patients remotely after the mini-lecture (Group III).

\section{DISCUSSION}

Our study showed that promoting awareness on radiation exposure facilitated significant reductions in fluoroscopic time and radiation dose during $\mathrm{CA}$ for $\mathrm{AF}$, and that the effects of the educational intervention persisted for a long period, even in more complex cases.

Over the past years, awareness of the risks associated with ionising radiation has increased. The estimated lifetime risk of cancer ranges between 1/2000 and 1/1000 per single cardiovascular procedure, ${ }^{2}$ and increases in younger patients and with repeated procedures. As the risk is not negligible for the medical staff, the ALARA principle should always be followed.

\section{Mapping technologies for radiation reduction}

Recent advance in 3D-EAM has reduced the radiation exposure during CA significantly, ${ }^{5}$ and a European survey showed that non-fluoroscopic mapping systems are available in more than $65 \%$ of centres that perform $\mathrm{CA}^{10}$ However, these techniques, including 3D-EAM, require a change in work flow, certain experiences in CA, and a learning curve to reduce the ionising radiation exposure. There have been reports of CA with zero fluoroscopy using intracardiac echocardiography. ${ }^{11}$ Contact force technology has also been reported to reduce the fluoroscopic time effectively. ${ }^{12} 13$ In our study, all the patients underwent $\mathrm{CA}$ for AF using 3D-EAM, and contact force monitoring catheters were used in a majority of cases.



Number of patients

Figure 2 Chronological radiation dose for each patient. Blue bar: patients prior to the mini-lecture; green bar: patients immediately after the mini lecture; red bar. patients remotely after the mini-lecture. 


\section{Promoting awareness on radiation reduction}

Promoting awareness on radiation exposure using mini-lecture is simple, yet very effective, in achieving a reduction in radiation exposure. Precautions such as avoiding the cine acquisition, ensuring appropriate patient position and table height, minimising the left anterior oblique (LAO) view and using appropriately adjusted collimation were included in the mini-course lecture.

\section{Study limitations}

The limitations to our study are as follows: (1) it was a single centre study, and a relatively small number of patients were included; (2) the available tools, mapping systems and ablation strategies varied over the study period.

\section{CONCLUSION}

Promoting awareness on radiation exposure significantly reduced the fluoroscopic times and radiation doses during $\mathrm{CA}$ for $\mathrm{AF}$, and the effects of the educational intervention persisted even at remote periods following the procedure.

Contributors Each author has contributed significantly to the submitted work. YM was the first investigator of this study. KS organised this study. AU, MK, ST, MN, YM, $\mathrm{NN}, \mathrm{KH}, \mathrm{ME}, \mathrm{IT}, \mathrm{AM}, \mathrm{YH}$ and TS collected data.

Funding The authors have not declared a specific grant for this research from any funding agency in the public, commercial or not-for-profit sectors.

Competing interests None declared.

Patient consent for publication Obtained.

Ethics approval This study was approved by the institutional review board, and written informed consent was obtained from all patients and laboratory staff.

Provenance and peer review Not commissioned; externally peer reviewed.

Data availability statement No additional data are available.

Open access This is an open access article distributed in accordance with the Creative Commons Attribution Non Commercial (CC BY-NC 4.0) license, which permits others to distribute, remix, adapt, build upon this work non-commercially, and license their derivative works on different terms, provided the original work is properly cited, appropriate credit is given, any changes made indicated, and the use is non-commercial. See: http://creativecommons.org/licenses/by-nc/4.0/.

\section{REFERENCES}

1. Calkins H, Hindricks G, Cappato R, et al. HRS/EHRA/ECAS/APHRS/ SOLAECE expert consensus statement on catheter and surgical ablation of atrial fibrillation: Executive summary. J Arrhythmia 2017;2017:369-409.

2. Roguin A, Goldstein J, Bar O, et al. Brain and neck tumors among physicians performing interventional procedures. Am J Cardiol 2013;111:1368-72.

3. Ciraj-Bjelac O, Rehani MM, Sim KH, et al. Risk for radiation-induced cataract for staff in interventional cardiology: is there reason for concern? Catheter Cardiovasc Interv 2010;76:826-34.

4. Christoph M, Wunderlich C, Moebius S, et al. Fluoroscopy integrated $3 \mathrm{D}$ mapping significantly reduces radiation exposure during ablation for a wide spectrum of cardiac arrhythmias. Europace 2015;17:928-37.

5. Thibault $\mathrm{B}$, Mondésert $\mathrm{B}$, Macle $\mathrm{L}$, et al. Reducing radiation exposure during crt implant procedures: single-center experience with lowdose fluoroscopy settings and a Sensor-Based navigation system (MediGuide). J Cardiovasc Electrophysiol 2016;27:1337-43.

6. Caponi D, Corleto A, Scaglione M, et al. Ablation of atrial fibrillation: does the addition of three-dimensional magnetic resonance imaging of the left atrium to electroanatomic mapping improve the clinical outcome? Europace 2010;12:1098-104.

7. Georges J-L, Livarek B, Gibault-Genty G, et al. Reduction of radiation delivered to patients undergoing invasive coronary procedures. Effect of a programme for dose reduction based on radiation-protection training. Arch Cardiovasc Dis 2009;102:821-7.

8. Kuon E, Weitmann K, Hoffmann W, et al. Multicenter long-term validation of a minicourse in radiation-reducing techniques in the catheterization laboratory. Am J Cardiol 2015;115:367-73.

9. Sheyn DD, Racadio JM, Ying J, et al. Efficacy of a radiation safety education initiative in reducing radiation exposure in the pediatric IR suite. Pediatr Radiol 2008;38:669-74.

10. Pison L, Proclemer A, Bongiorni MG, et al. Imaging techniques in electrophysiology and implantable device procedures: results of the European heart rhythm association survey. Europace 2013;15:1333-6.

11. Luani B, Zrenner B, Basho M, Genz C, et al. Zero-fluoroscopy cryothermal ablation of atrioventricular nodal re-entry tachycardia guided by endovascular and endocardial catheter visualization using intracardiac echocardiography (Ice\&ICE Trial). J Cardiovasc Electrophysiol 2018;29:160-6.

12. Lee G, Hunter RJ, Lovell MJ, et al. Use of a contact force-sensing ablation catheter with advanced catheter location significantly reduces fluoroscopy time and radiation dose in catheter ablation of atrial fibrillation. Europace 2016;18:211-8.

13. Zhang JQ, Yu RH, Liang JB, et al. Reconstruction left atrium and isolation pulmonary veins of paroxysmal atrial fibrillation using single contact force catheter with zero x-ray exposure: a consort study. Medicine 2017;96:e7726. 